\title{
Long-term Outcome of Endoscopic Retrograde Biliary Drainage of Biliary Stricture Following Living Donor Liver Transplantation
}

\author{
Jae Keun Park ${ }^{1}$, Ju-II Yang ${ }^{2}$, Jong Kyun Lee ${ }^{1}$, Joo Kyung Park ${ }^{1}$, Kwang Hyuck Lee ${ }^{1}$, Kyu Taek Lee ${ }^{1}$, Jae-Won Joh ${ }^{3}$, Choon \\ Hyuck David Kwon ${ }^{3}$, and Jong Man Kim ${ }^{3}$ \\ ${ }^{1}$ Division of Gastroenterology, Department of Medicine, Samsung Medical Center, Sungkyunkwan University School of Medicine, Seoul, \\ ${ }^{2}$ Division of Gastroenterology, Department of Internal Medicine, Good Gangan Hospital, Busan, and ${ }^{3}$ Department of Surgery, Samsung Medical \\ Center, Sungkyunkwan University School of Medicine, Seoul, Korea
}

Background/Aims: Biliary strictures remain one of the most challenging aspects after living donor liver transplantation (LDLT). The aim of this study was to assess long-term outcome of endoscopic treatment of biliary strictures occurring after LDLT and to identify risk factors of recurrent biliary strictures following endoscopic retrograde biliary drainage (ERBD) in LDLT. Methods: A total of 1,106 patients underwent LDLT from May 1995 to May 2014. We compared the risk factors between patients with and without recurrent biliary strictures. Results: Biliary strictures developed in $24.0 \%$ of patients. Technical success rate of ERBD for biliary stricture after LDLT was 66.2\% (145/219). Among 145 patients managed by endoscopic drainage, stricture resolution occurred in 69 with median duration of stent indwelling of 13.6 months (range, 0.5 to 67.3 months), and stricture recurrence was seen in $20(21.3 \%)$ out of 94 . The median recurrence-free duration after final endoscopic success was 13.1 months (range, 0.5 to 67.3 months). Older donor age (hazard ratio [HR], 1.10; 95\% confidence interval [Cl], 1.03 to $1.17 ; \mathrm{p}=0.004)$ and non-B, non-C liver cirrhosis (HR, 5.10; 95\% Cl, 1.10 to 25.00; $\mathrm{p}=0.043$ ) were associated with higher recurrence of biliary stricture. Conclusions: Long-term stricture resolution rate after ERBD insertion for biliary stricture occurring after LDLT was $73.4 \%$. Clinicians should pay careful attention during following-up to decide when to remove ERBD in patients who have factors associated with recurrent biliary strictures. (Gut Liver 2020;14:125-134)

Key Words: Biliary; Stricture; Endoscopic; Liver transplantation

\section{INTRODUCTION}

Liver transplantation (LT) has become a lifesaving technique for patients with end-stage liver disease. With improved survival of transplanted liver, biliary complications have become an increasing concern in patients with prolonged survival following LT. Biliary complications, including biliary strictures, bile leaks, stones, and ampullary dysfunction, have remained significant causes of morbidity and mortality after LT. ${ }^{1}$ Biliary stricture is the most common and intractable complication in adult living donor liver transplantation (LDLT). ${ }^{2,3}$ Bile duct strictures have been estimated to occur in 12\% to 35.6\% of all LDLT patients. ${ }^{2,45}$ Previous studies have reported that biliary stricture typically developed in late post-LT period ( $>3$ months), among those biliary complications. ${ }^{6-9}$ Biliary strictures are the major causes of morbidity after LDLT. Furthermore, biliary strictures are more complicated and difficult to be resolved after LDLT than deceased donor LT. ${ }^{2,4,10,11}$

Biliary strictures can be managed with endoscopic procedure, percutaneous approach, or surgical method. Nowadays, endoscopic procedures have shown marked improvement. They are the treatment of choice in patients with biliary strictures after LDLT. $^{12-14}$ Patients with biliary strictures that occur after LDLT with duct-to-duct biliary anastomosis is routinely undergo endoscopic retrograde cholangiopancreatography (ERCP) to treat biliary stricture. Advantages of ERCP are easy endoscopic accessibility of the stricture and relatively less invasiveness than percutaneous approach or surgical method. In addition, endoscopic procedures have been successfully used to manage anastomotic stricture and non-anastomotic stricture following LDLT. ${ }^{15}$

\footnotetext{
Correspondence to: Jong Kyun Lee

Division of Gastroenterology, Department of Medicine, Samsung Medical Center, Sungkyunkwan University School of Medicine, 81 Irwon-ro, Gangnam-gu, Seoul 06351, Korea

Tel: +82-2-3410-3409, Fax: +82-2-3410-6983, E-mail: jongk.lee@samsung.com

Received on April 29, 2018. Revised on November 12, 2018. Accepted on December 11, 2018. Published online August $14,2019$.

pISSN 1976-2283 eISSN 2005-1212 https://doi.org/10.5009/gnl18387

Jae Keun Park and Ju-Il Yang contributed equally to this work as first authors.

(a) This is an Open Access article distributed under the terms of the Creative Commons Attribution Non-Commercial License (http://creativecommons.org/licenses/by-nc/4.0) which permits unrestricted non-commercial use, distribution, and reproduction in any medium, provided the original work is properly cited.
} 
Close surveillance for biliary stricture appears to be necessary for at least three years after LDLT. ${ }^{16}$ However, the risk factors of biliary stricture and optimal time for a clinician to remove the endoscopic retrograde biliary drainage (ERBD) after endoscopic treatment of biliary stricture of LDLT are unclear. Severe biliary complications such as cholangitis can occur when the endoscopist removes the ERBD too early. On the other hand, patient can spend unnecessary medical cost on further ERCP to change ERBD when it is removed too late. ${ }^{17}$

The aim of this study was to assess long-term outcome of endoscopic treatment of biliary stricture occurring after LDLT and to identify risk factors of recurrent biliary stricture after endoscopic treatment following LDLT.

\section{MATERIALS AND METHODS}

This study enrolled 1,441 patients who underwent LT between May 1996 and May 2014 at Samsung Medical Center. Of these, 335 were excluded because of retransplantation $(n=55)$ or deceased donor LT $(\mathrm{n}=280)$. Of the remaining 1,106 LDLT patients, biliary complications occurred in 304 patients, including biliary stricture $(n=265)$, bile leak and biloma $(n=32)$, and biliary stricture with bile leak ( $\mathrm{n}=7$ ). Among these 265 patients, 241 with clinically suspected biliary stricture underwent ERCP. Nine patients received the reconstructive surgery and 15 received percutaneous transhepatic biliary drainage in 24 patients who did not undergo ERCP. Patients were assessed for biliary stricture was assessed when they presented with symptoms, such as abdominal pain, jaundice, and an itching sensation when patients showed abnormal laboratory findings including elevated liver enzyme levels or hyperbilirubinemia, or when patients had dilated bile duct on ultrasonography or computed tomography. ${ }^{18}$ If patients were diagnosed with biliary strictures, ERCPs with
ERBDs were performed.

Among 241 patients who underwent ERCP, 22 individuals displayed a minimal biliary stricture that needed only balloon dilatation while 74 patients did not receive ERBD (Fig. 1).

We followed up 145 patients with successful ERBD for more than 12 months. ERBDs were removed in 94 due to improvement of biliary stricture. Among these 94 patients in the ERBD removal group, 25 experienced recurrence of biliary stricture. Five of these 25 recurrences occurred within the first 3 months and 20 recurred after 3 months. Occurrence of the biliary stricture within the 3 months after ERBD removal appeared to be a residual stricture and not a recurrence (Fig. 2). ${ }^{6-9}$ We compared the clinical factors between patients with and without recur-

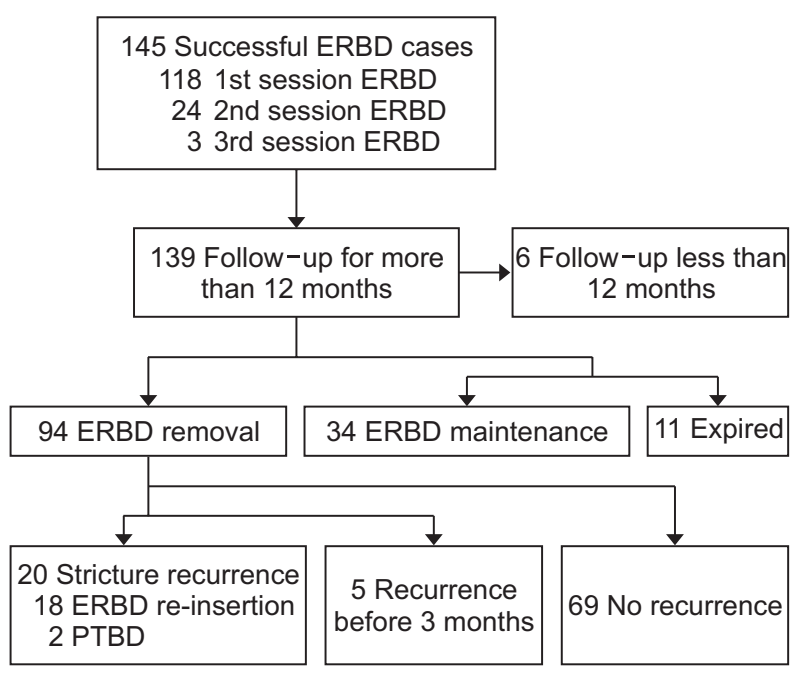

Fig. 2. Algorithm for comparison of progress in patients with initially successful endoscopic treatment.

ERBD, endoscopic retrograde biliary drainage; PTBD, percutaneous transhepatic biliary drainage

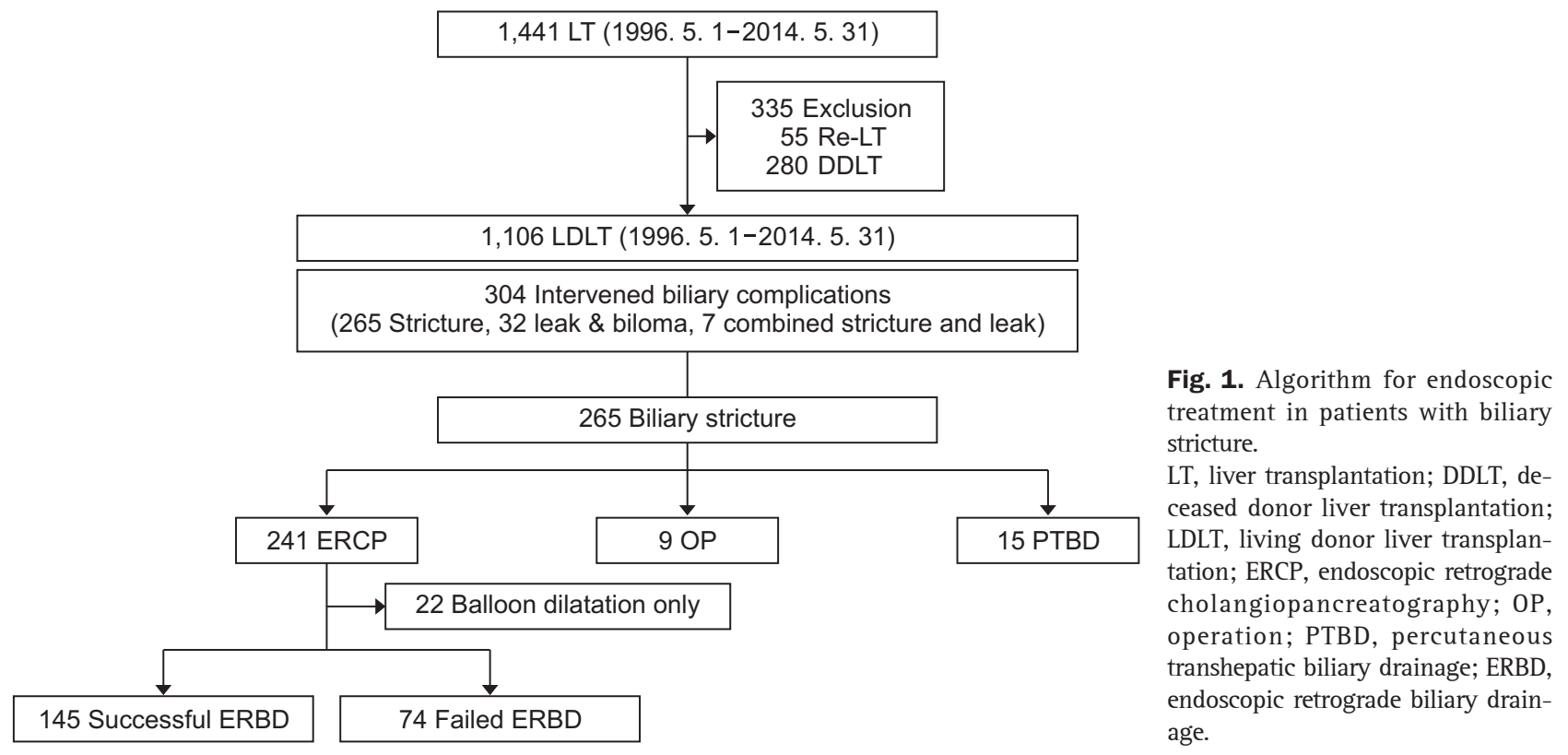




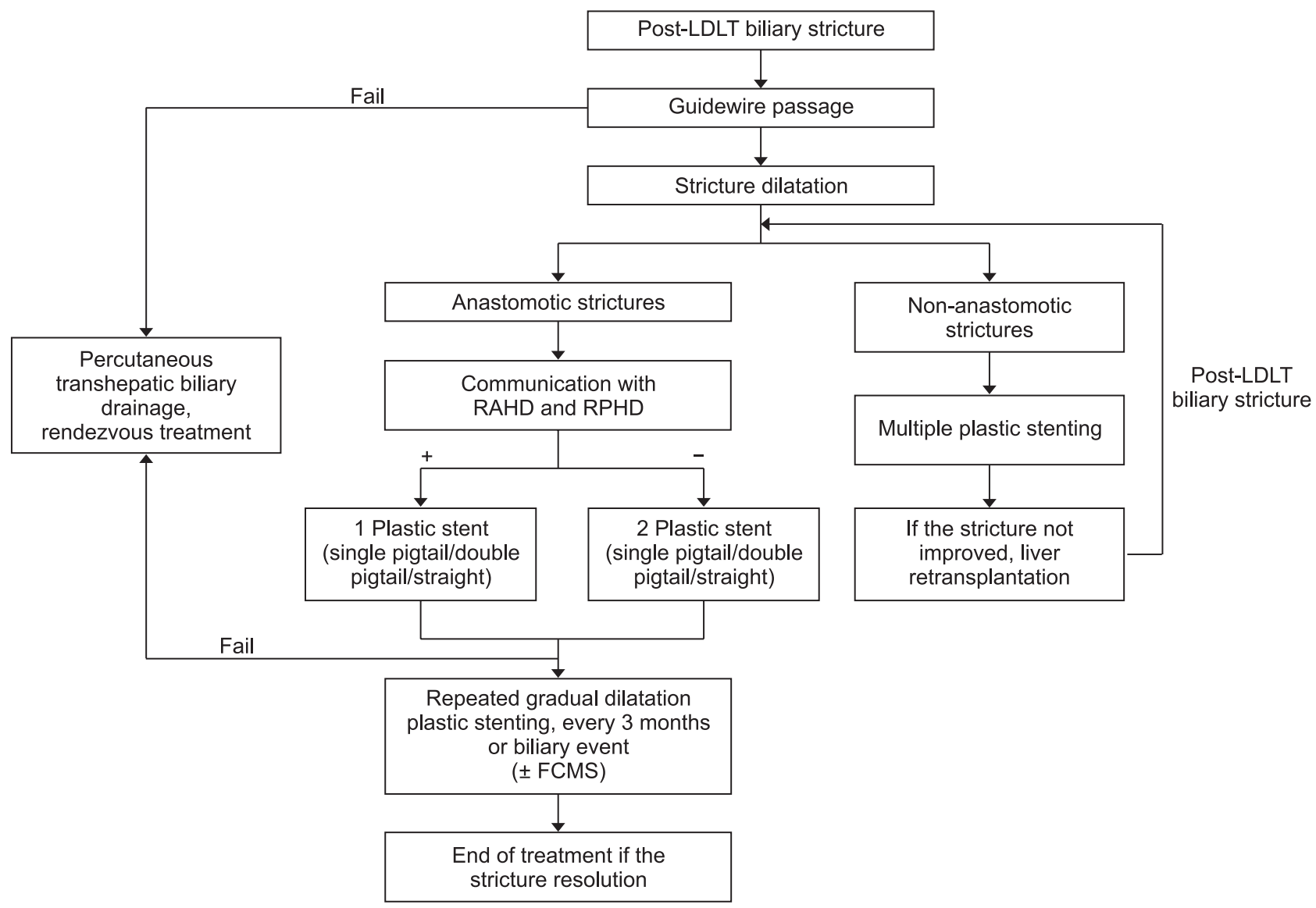

Fig. 3. Algorithm of the treatment of post-LDLT biliary stricture.

LDLT, living donor liver transplantation; RAHD, right anterior hepatic duct; RPHD, right posterior hepatic duct; FCMS, full-covered metal stents.

Table 1. The Baseline Characteristics of the 145 Patients Who Underwent Successful ERBD ( $\mathrm{n}=145)$

\begin{tabular}{lc}
\hline \multicolumn{1}{c}{ Characteristic } & Value \\
\hline Age, yr & $53(16-69)$ \\
Sex, male/female & $122(84) / 23(16)$ \\
Child-Pugh-Turcotte class & $29(20) / 46(32) / 70(48)$ \\
at the time of LT, A/B/C & \\
Underlying disease at the time of LT & $74(51)$ \\
Hepatocellular carcinoma & $53(37)$ \\
Hepatitis B virus or hepatis C virus & \\
related cirrhosis & $18(12)$ \\
Cirrhosis by other causes & $6.6(0.7-93.4)$ \\
LT to ERCP interval, mo &
\end{tabular}

Data are presented as median (range) or number (\%).

ERBD, endoscopic retrograde biliary drainage; LT, liver transplantation; ERCP, endoscopic retrograde cholangiopancreatography.

rence of biliary stricture.

To identify the risk factors of the recurrent biliary stricture after endoscopic treatment following LDLT, we analyzed recipient factors, donor factors, laboratory results, LT-related factors, and endoscopic procedure-related factors. ERCP images and medical
Table 2. Treatment Outcomes of Endoscopic Therapy of Post-LDLT Biliary Stricture

\begin{tabular}{lc}
\hline \multicolumn{1}{c}{ Treatment outcome } & Value \\
\hline Biliary stricture & $265 / 1,106(24.0)$ \\
Follow-up, mo & $27.1(4.2-48.1)$ \\
Immediate endoscopic success & $118 / 219(53.9)$ \\
Final endoscopic success & $145 / 219(66.2)$ \\
$\quad$ ERBD removal & $94 / 145(64.8)$ \\
ERCP session for final endoscopic success & $1(1-3)$ \\
Duration for final endoscopic success, day & $1(1-44)$ \\
Stricture recurrence after final & $20 / 94(21.3)$ \\
endoscopic success & \\
Recurrence-free duration after & $13.1(0.5-67.3)$ \\
final endoscopic success, mo & \\
\hline
\end{tabular}

Data are presented as number/number (\%) or median (range).

LDLT, living donor liver transplantation; ERBD, endoscopic retrograde biliary drainage; ERCP, endoscopic retrograde cholangiopancreatography.

records were reviewed retrospectively. The Institutional Review Board of Samsung Medical Center approved the study protocol (IRB number: 2016-01-054). Informed consent was waived. 
Table 3. Comparison of Recipient, Donor, LT- and Endoscopic Procedure-Related Factors Associated with Recurrence after ERBD Removal

\begin{tabular}{|c|c|c|c|}
\hline & Resolution group $(n=69)$ & Recurrence group $(n=20)$ & p-value \\
\hline \multicolumn{4}{|l|}{ Recipient factor } \\
\hline \multicolumn{4}{|l|}{ Underlying disease at the time of LT } \\
\hline Hepatocellular carcinoma & $34(49)$ & $8(40)$ & 0.131 \\
\hline Hepatitis B or C virus-related cirrhosis & $24(35)$ & $11(55)$ & 0.559 \\
\hline Cirrhosis by other causes & $11(16)$ & $1(5)$ & 0.096 \\
\hline Age, yr & $52(16-69)$ & $55(43-68)$ & 0.144 \\
\hline Sex, male/female & $60(87) / 9(13)$ & $18(90) / 2(10)$ & 0.826 \\
\hline Diabetes mellitus & $12(17.4)$ & $5(25)$ & 0.327 \\
\hline Hypertension & $10(14.5)$ & $1(5)$ & 0.329 \\
\hline Child-Turcotte-Pugh class at the time of LT (A/B/C) & $15(22) / 23(33) / 31(45)$ & $2(10) / 7(35) / 11(55)$ & 0.195 \\
\hline Meld score at the time of LT & $19.5 \pm 11.3$ & $20.6 \pm 11.5$ & 0.385 \\
\hline \multicolumn{4}{|l|}{ Lab at the time of LT } \\
\hline Total bilirubin & $10.9 \pm 16.2$ & $11.9 \pm 17.1$ & 0.809 \\
\hline AST & $164 \pm 474.8$ & $187.15 \pm 529.8$ & 0.214 \\
\hline ALT & $110.9 \pm 234.43$ & $125.1 \pm 257.5$ & 0.275 \\
\hline GGT & $54.2 \pm 49.4$ & $56.4 \pm 51.7$ & 0.341 \\
\hline Albumin & $3.1 \pm 0.4$ & $3.1 \pm 0.7$ & 0.077 \\
\hline INR & $2.3 \pm 4.9$ & $2.5 \pm 5.4$ & 0.870 \\
\hline Poor glucose control at the time of next morning after LT & $59(85.5)$ & $18(90)$ & 0.712 \\
\hline \multicolumn{4}{|l|}{ Donor factor } \\
\hline Donor age, yr & $29(16-57)$ & $37(17-62)$ & $0.007^{*}$ \\
\hline Donor sex, male/female & $55(80) / 14(20)$ & $13(65) / 7(35)$ & 0.247 \\
\hline \multicolumn{4}{|l|}{ LT operation related factor } \\
\hline Ductoplasty & $12(17.4)$ & $4(20)$ & 0.942 \\
\hline Operation time, min & $537.1 \pm 123.4$ & $543.2 \pm 120.3$ & 0.466 \\
\hline Cold ischemia time, min & $124.7 \pm 118.3$ & $118.4 \pm 114.2$ & 0.820 \\
\hline Warm ischemia time, min & $37.8 \pm 23.6$ & $38.3 \pm 26.2$ & 0.155 \\
\hline Ductal stent insertion & $14(20.3)$ & $2(10)$ & 0.379 \\
\hline Bile duct size, mm & $5.7 \pm 2.0$ & $5.7 \pm 2.1$ & 0.524 \\
\hline Multiplicity of grafted bile ducts & $18(26.1)$ & $8(40)$ & 0.289 \\
\hline No. of donor ducts, $1 / 2 / 3$ & $50(72) / 19(28) / 0$ & $12(60) / 7(35) / 1(5)$ & 0.524 \\
\hline \multicolumn{4}{|l|}{ Endoscopic procedure related factor } \\
\hline LT-to-ERCP interval, mo & $6.9(0.7-93.4)$ & $5.4(0.7-63.1)$ & 0.992 \\
\hline ERBD sessions to success, 1 st/2nd/3rd & $57(83) / 10(14) / 2(3)$ & $17(85) / 3(15) / 0$ & 0.762 \\
\hline Total ERBD dimension, Fr & $11.7 \pm 12.3$ & $11.6 \pm 10.8$ & 0.765 \\
\hline Full-covered metal stent & $7(10.1)$ & $1(5)$ & 0.555 \\
\hline Sessions until ERBD removal & $3(1-15)$ & $3(1-13)$ & 0.724 \\
\hline Duration of ERBD indwelling, mo & $13.6(0.5-67.3)$ & $9.0(3.3-61.8)$ & 0.509 \\
\hline \multicolumn{4}{|l|}{ Stricture morphology } \\
\hline Wide stricture & $20(29)$ & $5(25)$ & 0.821 \\
\hline Narrow stricture & $28(41)$ & $7(35)$ & 0.372 \\
\hline Separate duct & $20(29)$ & $6(30)$ & 0.986 \\
\hline Non-visualization of the proximal duct & $1(1)$ & $2(10)$ & 0.539 \\
\hline
\end{tabular}


Table 3. Continued

\begin{tabular}{|c|c|c|c|}
\hline & Resolution group $(\mathrm{n}=69)$ & Recurrence group $(\mathrm{n}=20)$ & p-value \\
\hline \multicolumn{4}{|c|}{ Tip shape of the distal duct } \\
\hline Tapered tip & $54(78)$ & $14(70)$ & 1.000 \\
\hline Round tip & $15(22)$ & $6(30)$ & 0.589 \\
\hline \multicolumn{4}{|c|}{ Angle between the proximal and distal ducts } \\
\hline $0^{\circ}-30^{\circ}$ & $33(48)$ & $9(45)$ & 1.000 \\
\hline$>30^{\circ} \& \leq 60^{\circ}$ & $30(43)$ & $9(45)$ & 0.372 \\
\hline$>60^{\circ} \& \leq 90^{\circ}$ & $2(3)$ & $2(10)$ & 0.986 \\
\hline$>90^{\circ}$ or S shape & $4(6)$ & 0 & 0.539 \\
\hline
\end{tabular}

Data are presented as number (\%), median (range), or mean \pm SD.

LT, liver transplantation; ERBD, endoscopic retrograde biliary drainage; AST, aspartate transaminase; ALT, alanine aminotransaminase; GGT, gamma-glutamyl transferase; INR, international normalized ratio; ERCP, endoscopic retrograde cholangiopancreatography. *p-value $<0.05$.

\section{Endoscopic procedures}

The ERCP techniques for LDLT patients were similar to those for patients with benign strictures of biliary system (Fig. 3). After bile duct cannulation, an injection of a contrast dye revealed the distal and proximal parts of the anastomosis. When proximal part was not visualized after a simple dye injection, balloon-assisted cholangiography was tried. After biliary strictures were confirmed, small biliary sphincterotomy was performed and a guidewire was passed through the biliary strictures. Stricture were dilated with a 6- to $10-\mathrm{mm}$ dilation balloon at 3 to 11 atm for 30 seconds. If the proximal bile ducts were separated, two guidewires were inserted to both anterior and posterior intrahepatic bile ducts. One or two plastic stents $(7,8.5$, or 10 Fr) and/or fully covered metal stents (FCMS) were then placed across the stricture for drainage. Proportion of plastic stent and FCMS among the 89 ERBD removal patients were 91.0\% (81 out of 89) and 9\% (8 out of 89), respectively. We decided the number, size and form of the stents based on the stricture morphology, the tip shape of the distal duct and the angle between the proximal and distal ducts. ERCP was conducted electively at a 3-month interval or in patients with evidence of cholangitis or liver biochemistry abnormality for ERBD exchange. Previously inserted ERBD was removed by snares or alligator retrieval forceps. End of treatment was determined by stricture resolution using cholangiogram of biliary stricture resolution $(>50 \%$ than proximal duct), contrast passage of the stricture site after ERBD removal and balloon sweeping of the stricture site without resistance. In most cases of failed ERBD, the most difficult steps were the guidewire passages. Success of primary endoscopic management was defined as the successful placement of a ERBD through the stricture site.

\section{Definition of success and recurrence after endoscopic procedure}

Resolution of biliary stricture with endoscopic intervention was defined as the presence of the following: (1) resolution of cholestasis, (2) complete resolution of clinical symptoms, (3) no subsequent requirement for interventional procedures, and (4) biliary stricture resolution ( $>50 \%$ than proximal duct) on cholangiogram. Biliary stricture recurrence was defined as the presence of the following: (1) the presence of recurrent stricture on cholangiography after resolution of stricture, at least 3 months after the removal of stent, (2) requirement of additional endoscopic procedure for the resolution of stricture.

\section{Statistical analyses}

The Pearson chi-square test and the Student t-test were used to identify statistical significances of different clinical variables. Multivariate analysis with the logistic regression was performed for variables with $\mathrm{p}<0.05$ on simple logistic regression. Statistical analyses were executed using Stata 11.1 software (StataCorp., College Station, TX, USA).

\section{RESULTS}

Baseline characteristics of the 145 patients with successful ERBD are presented in Table 1. Their median age was 53 years (range, 16 to 69 years). Most patients (84\%) of them were males. Underlying disease at the time of LT was hepatocellular carcinoma (HCC) in 74 (51\%), hepatitis B virus or hepatitis C virus related cirrhosis in 53 (37\%), and cirrhosis by other causes in 18 (12\%). The median interval between the time of LT and endoscopic procedure was 6.6 months (range, 0.79 to 93.4 months) (Table 1).

Following LDLT, biliary stricture occurred in 265 (24.0\%) of 1,106 LDLT patients (24.0\%). The success rate of endoscopic treatment of biliary stricture was $66.2 \%$ (145/219). Recurrence 
rate of biliary stricture after endoscopic treatment was 21.3\%. Median follow-up was 27.1 months (range, 4.2 to 48.1 months) (Table 2). Two hundred and sixty-five cases were diagnosed with biliary stricture after LDLT, and ERCP was attempted in that of 241 cases. Of these 241 cases, biliary stricture was minimal in 22 cases. Thus, it was sufficient to improve biliary stricture with only balloon dilatation. Then, we tried the ERBD in 219 cases. ERBD was finally successful in 66.2\% (145/219) (Fig. 1) and performed successfully at the first time in 118 (53.9\%) (Fig. 2). Among 145 patients managed by endoscopic drainage, structure resolution occurred in 69 (69/145) with median duration of ERBD indwelling of 13.6 months (range, 0.5 to 67.3 months). Stricture recurrence was seen in 21.3\% (20/94). The median recurence-free duration after final endoscopic success was 13.1 months (range, 0.5 to 67.3 months). Median number of ERCP sessions and duration needed for final endoscopic success was 1 (range, 1 to 3) and 1 day (range, 1 to 44 days), respectively (Table 2).

Underlying diseases at the time of LT were HCC, cirrhosis due to hepatitis B virus or hepatitis C virus, and cirrhosis by other causes. Rates of these three underlying diseases were not significantly different between resolution and recurrence groups ( $\mathrm{p}=0.131, \mathrm{p}=0.559$, and $\mathrm{p}=0.096$, respectively). Recipient age and sex ratio were similar between the resolution and recurrence groups ( $p=0.144$ and $p=0.826$, respectively). There were no significant differences the rate of diabetes mellitus ( $p=0.327$ ), hypertension ( $p=0.329)$, Child-Turcotte-Pugh class at time of LT ( $p=0.195)$, MELD score at the time of LT ( $p=0.385)$, or donor male/female sex ratio $(\mathrm{p}=0.247)$. At the time of $\mathrm{LT}$, liver biochemistry analyses were similar in the two groups; poor glucose control the next morning after LT was also similar in the two groups ( $\mathrm{p}=0.712)$. Median donor age in the resolution group (29 years; range, 16 to 57 years) was significantly younger than in the recurrence group (37 years; range, 17 to 62 years) $(p=0.007)$ (Table 3).

Group similarities included LT-related factors of ductoplasty ( $\mathrm{p}=0.942)$, operation time $(\mathrm{p}=0.466)$, cold ischemia time $(p=0.820)$, warm ischemia time $(p=0.155)$, ductal stent insertion rate $(p=0.397)$, bile duct size $(p=0.524)$, multiplicity rate of grafted bile ducts $(\mathrm{p}=0.289)$, and number of donor ducts $1 / 2 / 3$ ( $p=0.524)$ (Table 3). Further similarities between the two groups included LT-to-ERCP interval ( $\mathrm{p}=0.992)$, number of ERBD sessions to success $(p=0.762)$, total ERBD diameter $(p=0.765)$, FCMS $(p=0.555)$, median number of sessions until ERBD removal ( $p=0.724)$, median duration of ERBD indwelling $(p=0.509)$, wide stricture morphology $(\mathrm{p}=0.821)$, narrow stricture morphology ( $p=0.372$ ), non-visualization of the proximal duct $(p=0.539)$, tapered and round shape of the distal ducts $(p=1.000$ and $p=0.589$, respectively), and angles between the proximal and distal ducts (Table 3, Fig. 4).

Table 4 shows the multivariate-adjusted hazard ratios (HRs) and 95\% confidence intervals for the recurrence of biliary stric-
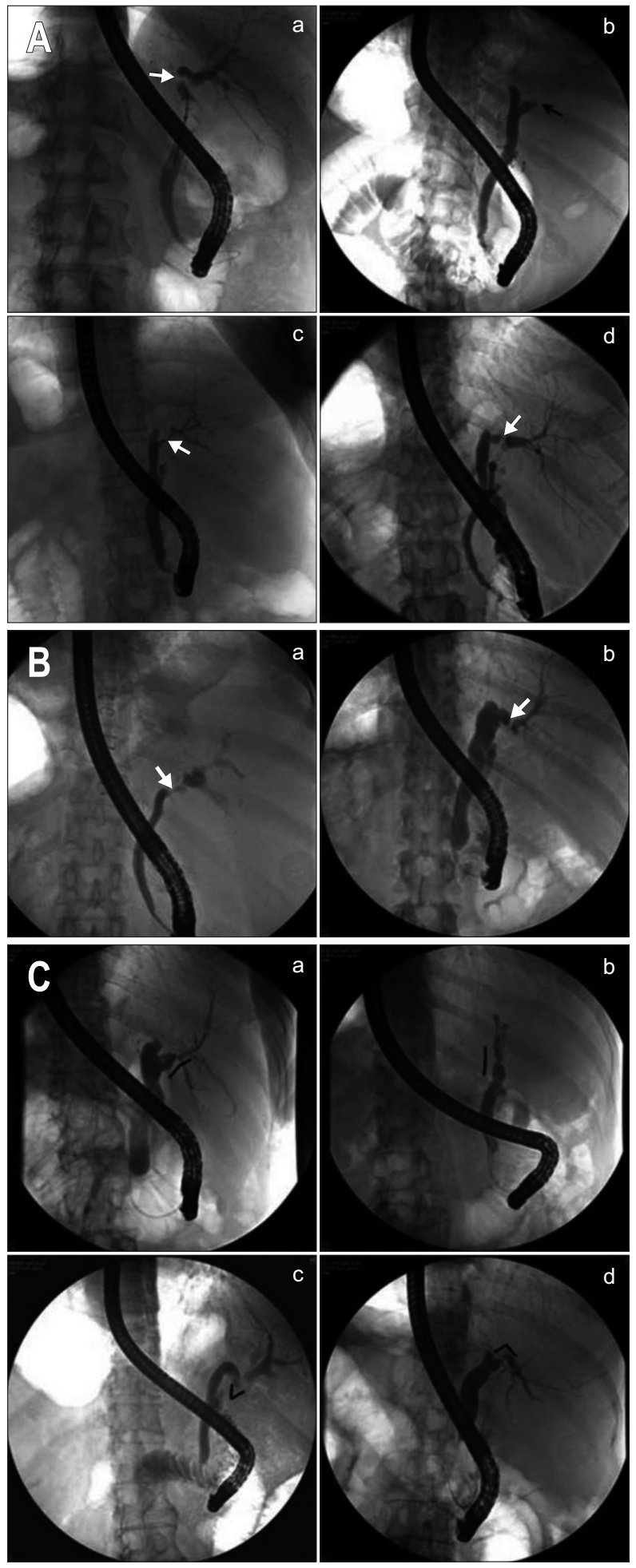

Fig. 4. Representative cases of biliary strictures according to the cholangiographic findings. (A) Separate duct type (arrow, a; the proximal duct is visualized, but the stricture site is not visualized), non-visualization of the proximal duct (b), wide stricture type (arrow, c; the stricture site is visualized with a luminal diameter $>2 \mathrm{~mm}$ ) and narrow stricture type (arrow, d; the stricture site is visualized with a luminal diameter $\leq 2 \mathrm{~mm}$ ). (B) Tapered shapes (arrow, a) and distal ducts with round (arrow, b). (C) Angles between the proximal and distal ducts of $30^{\circ}$ to $60^{\circ}$ (a), $0^{\circ}$ to $30^{\circ}$ (b), $>90^{\circ}$ (c; an S shape and $60^{\circ}$ to $90^{\circ}$ [d]). 
Table 4. Multivariate Analysis of the Factors of Recurrence after Removal of ERBD

\begin{tabular}{|c|c|c|c|}
\hline & $\mathrm{HR}$ & $95 \%$ CI & p-value \\
\hline \multicolumn{4}{|l|}{ Underlying disease at the time of LT } \\
\hline Hepatocellular carcinoma & 1 & & 1.000 \\
\hline Hepatitis B virus- or hepatitis C virus-related cirrhosis & 0.60 & $0.00-8.40$ & 0.683 \\
\hline Cirrhosis by other causes & 5.10 & $1.10-25.00$ & $0.043^{*}$ \\
\hline Recipient age & 1.07 & $0.98-1.18$ & 0.123 \\
\hline Donor age & 1.10 & $1.03-1.17$ & $0.004^{*}$ \\
\hline No. of donor ducts, $1 / 2 / 3$ & 2.50 & $0.68-9.22$ & 0.168 \\
\hline
\end{tabular}

ERBD, endoscopic retrograde biliary drainage; HR, hazard ratio; CI, confidence interval; LT, liver transplantation. *p-values $<0.05$.

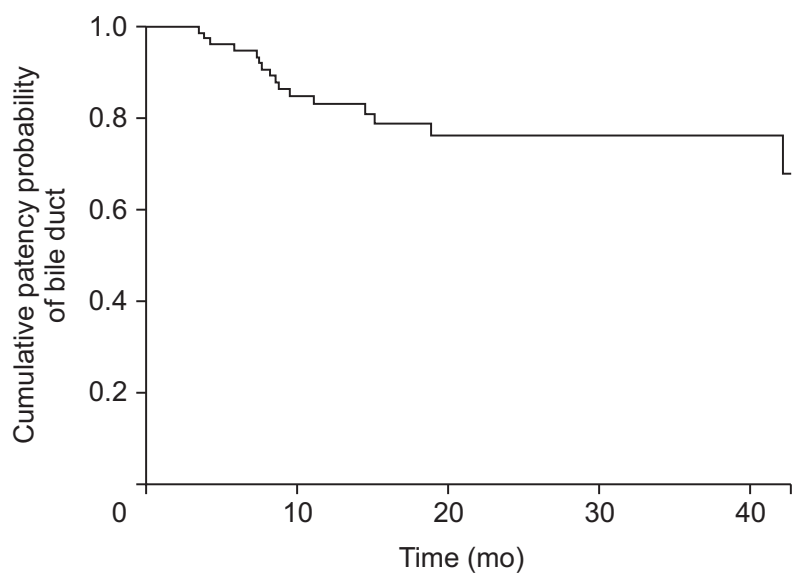

Fig. 5. The Kaplan-Meier curve of cumulative patency probability of bile duct according to time after endoscopic retrograde biliary drainage removal.

ture after removal of ERBD. Overall, the HRs on multivariateadjusted analysis revealed that cirrhosis by other causes (HR, 5.10; 95\% confidence interval, 1.10 to $25.00 ; \mathrm{p}=0.043$ ) and donor age (HR, 1.10; 95\% confidence interval, 1.03 to 1.17 ; $\mathrm{p}=0.004$ ) were independent predictive factors of the recurrence of biliary stricture after endoscopic treatment (Table 4).

Fig. 5 shows the Kaplan-Meier curve of cumulative patency probability of bile duct after ERBD removal. Among 94 patients, persistent stricture resolution was achieved in 69 patients (73.4\%) during the follow-up period (median, 27.1 months; range, 4.2 to 48.1 months). The recurrence of biliary stricture occurred in 25 patients (26.6 \%) of the ERBD removal group (Fig. 2). ERBD reinsertion was conducted in 23 patients of the recurrence group and the other two patients were managed with percutaneous transhepatic biliary drainage. There was no ERBD migration among the 18 ERBD re-inserted patients. Cholangitis was the most common post-ERCP complication among the 18 ERBD re-inserted patients $(2 / 18,11.1 \%)$. The other complication was pancreatitis $(1 / 18,5.6 \%)$. There was no patient who lost a graft due to complications of endoscopic management.

\section{DISCUSSION}

In our study, the causes at the time of LT and a donor age were associated with the recurrence of the biliary stricture following LDLT. Proven etiologic factors of biliary strictures after LT include were the small bile duct diameter, an unmatchedsize between recipient and graft bile ducts, tissue ischemia, tension at the anastomosis, infection, and other technical issues. ${ }^{19}$ However, the risk factors that influence the outcomes of the endoscopic management have not been well characterized. In the present study, we investigated recipient factors, donor factors, LT-related factors, and endoscopic procedure-related factors associated with recurrence of biliary stricture after ERBD removal.

In our study, non-B, non-C liver cirrhosis and donor age were independent predictive factors of the recurrence of biliary stricture after endoscopic treatment. These are the potential explanations for our results. First, cirrhosis by other causes such as toxic hepatitis, Budd-Chiari syndrome, Wilson disease and glycogen storage disease were not completely cured or controlled after LDLT. On the other hand, in the cases of HCC, LDLT was performed as an established curative treatment. And also, patients with hepatitis B virus or hepatitis C virus-related cirrhosis could be completely cured or controlled with antiviral agent including direct-acting antiviral for hepatitis C virus after LDLT. Second, regarding donor age, the younger the age, the lower the probability of being affected by these proven etiologic factors of biliary strictures after LT as mentioned above.

Initially, we postulated that complicated biliary strictures would be associated with recurrence after removal of ERBD. However, we found no significant association between recurrence and stricture morphology. A previous retrospective cohort study in another institution has revealed similar result. ${ }^{20}$ In fact, it was difficult to define the exact point of the anastomosis site and distinguish between anastomotic and non-anastomotic stricture on the cholangiography. ${ }^{21}$

Recently, endoscopic intervention for benign biliary strictures after LDLT has attempted to place maximum-sized and multiple stents and to maintain a longer duration of stenting in order to avoid recurrence. ${ }^{13,14,22}$ The failure rate of primary ERCP may be 
high in patients with late onset and delayed diagnosis of biliary stricture. ${ }^{17}$ The recurrence seemed to occur frequently in patients with a short duration of stenting, although it was not statistically significant in our study.

Biliary stricture formations are typically due to ischemia/ perfusion injury, vascular insufficiency, or fibrotic healing caused by improper technique. ${ }^{6,9}$ Plus, close surveillance for biliary stricture appears necessary for at least the first 3 years after LDLT. ${ }^{16}$ Elevated liver enzyme suggested biliary stricture following LDLT. Hyperbilirubinemia following LT can occur as a result of ischemia/perfusion injury, cytomegalovirus infection, acute rejection, and biliary stricture. ${ }^{23}$ In our study, liver biochemistry analyses were not significantly different between resolution and recurrence groups at the time of LT. Cholangiography is the gold standard diagnostically and in allowing therapeutic intervention in the same setting. ${ }^{24}$

Endoscopic procedures have progressed tremendously. They are considered the treatment of choice for biliary strictures after LDLT. $^{12}$ Recent studies have reported success rates of $68 \%$ to $86.4 \%$ in endoscopic intervention of LDLT to $86.4 \% .^{5,10,11,20}$ In our institution, ERBD was performed immediately in 118 (53.9\%) patients. After two or three endoscopic sessions, 145 (66.2\%) patients succeeded. This relatively low success rate compared to recent studies might be due to difference in study population, period and method (type of stent). One retrospective cohort study has found that the reason of the relatively low success rates is related to technically difficult endoscopic procedure in treatment of post-LDLT biliary stricture. ${ }^{20}$ The most common reason for the failure of endoscopic treatment is the inability to cannulate the stricture. ${ }^{10,25}$

The number of ERBD sessions to success was similar in the resolution and recurrence groups. In another study, an average of 6.3 endoscopic sessions and 122.7 months were required to achieve final endoscopic success. ${ }^{20}$ The median number of ERCP sessions for final endoscopic success was 1 (range, 1 to 3 ) and median follow-up month for patients with endoscopic therapy was 27.1 months (range, 4.2 to 48.1 months). Multiple sessions of balloon dilatation followed by the endoscopic placement of plastic stents is the most commonly adopted strategy for the treatment of anastomotic biliary stricture after LDLT. The success rates with multiple plastic stents could be higher with a more prolonged treatment of 12 months or longer. ${ }^{26}$

In this study, the median duration of LT-to-ERCP interval was 6.9 months (range, 0.7 to 93.4 months) in the resolution group and 5.4 months (range, 0.7 to 63.1 months) in the recurrence group. Strictures tend to occur at 5 to 8 months after orthotopic LT with the majority of them presenting within 1 year, ${ }^{9,27}$ although their prevalence might continue to increase with the time after transplantation. ${ }^{28}$ Current endoscopic strategies to correct biliary strictures following LT include balloon dilation and the placement of multiple side-by-side plastic stents. ${ }^{29}$ Recently, a study group has reported the long-term outcome of endoscopic biliary drainage after LDLT using inside-stent which is placed plastic stent proximal to the sphincter of Oddi without endoscopic sphincterotomy. ${ }^{30}$ One multicenter study has demonstrated the effectiveness of FCMS in the treatment of biliary stricture after LDLT. $^{31}$ In our study, FCMS were used in 10.14\% of cases in the resolution group and 5\% in the recurrence group. Only one recurrence case was noted in our study with FCMS. However, the number of patients treated with FCMS was insufficient for statistical significance.

Our study has several limitations. First, we used a retrospective cohort with the potential of selection bias. Participants who underwent LDLT and ERCP during an 18-year period were included. Due to this long study period, different gastroenterologists and surgeons were involved. This might have resulted in inter-observer or intra-observer variations. Second, as mentioned earlier, the definition of the anastomosis stricture site was not exactly determined. Sometimes, it could be very subjective on cholangiography. Thus, prospective validation studies with standardized anastomosis stricture site diagnoses are required to confirm our results. Third, we may have underestimated the rate of post-ERCP complications due to lack of description of subjective symptoms and irregular follow-up interval. Nevertheless, the present study has clinical significance in that it assessed long-term outcome of endoscopic treatment of biliary stricture occurring after LDLT and identified risk factors of recurrent biliary stricture after endoscopic treatment following LDLT in a large cohort study.

In conclusion, younger donor age was associated with lower recurrence rate while non-B, non-C liver cirrhosis such as toxic hepatitis, Budd-Chiari syndrome, Wilson disease, hepatitis A virus infection, and glycogen storage disease were associated with higher recurrence rate of biliary stricture. Long-term stricture resolution of the ERBD of biliary stricture occurring after LDLT was $73.4 \%$. Thus, clinician should be careful when performing ERBD removal. Close follow up is needed for cases with risk factors associated with recurrent biliary stricture.

\section{CONFLICTS OF INTEREST}

No potential conflict of interest relevant to this article was reported.

\section{AUTHOR CONTRIBUTIONS}

Conception and design, and/or acquisition of data, and/or analysis and interpretation of data: Jae Keun Park, J.I.Y., J.K.L. Drafting the article or revising it critically for important intellectual content: Joo Kyung Park, K.H.L., K.T.L., J.W.J., C.H.D.K., J.M.K. 


\section{ORCID}

Jae Keun Park

https://orcid.org/0000-0002-3367-1770

Ju-Il Yang

Jong Kyun Lee

https://orcid.org/0000-0002-2397-6087

https://orcid.org/0000-0002-9384-3079

Joo Kyung Park

https://orcid.org/0000-0002-9652-5287

Kwang Hyuck Lee

https://orcid.org/0000-0002-5558-0415

Kyu Taek Lee

https://orcid.org/0000-0003-2233-3511

Jae-Won Joh

https://orcid.org/0000-0003-1732-6210

Choon Hyuck David Kwon

https://orcid.org/0000-0002-1082-3321

Jong Man Kim

https://orcid.org/0000-0002-1903-8354

\section{REFERENCES}

1. Starzl TE, Putnam CW, Hansbrough JF, Porter KA, Reid HA. Biliary complications after liver transplantation: with special reference to the biliary cast syndrome and techniques of secondary duct repair. Surgery 1977;81:212-221.

2. Dulundu E, Sugawara Y, Sano K, et al. Duct-to-duct biliary reconstruction in adult living-donor liver transplantation. Transplantation 2004;78:574-579.

3. Fan ST, Lo CM, Liu CL, Tso WK, Wong J. Biliary reconstruction and complications of right lobe live donor liver transplantation. Ann Surg 2002;236:676-683.

4. Gondolesi GE, Varotti G, Florman SS, et al. Biliary complications in 96 consecutive right lobe living donor transplant recipients. Transplantation 2004;77:1842-1848.

5. Hisatsune H, Yazumi S, Egawa H, et al. Endoscopic management of biliary strictures after duct-to-duct biliary reconstruction in right-lobe living-donor liver transplantation. Transplantation 2003;76:810-815

6. Tung BY, Kimmey MB. Biliary complications of orthotopic liver transplantation. Dig Dis 1999;17:133-144.

7. Porayko MK, Kondo M, Steers JL. Liver transplantation: late complications of the biliary tract and their management. Semin Liver Dis 1995;15:139-155.

8. Testa G, Malagò M, Broelseh CE. Complications of biliary tract in liver transplantation. World J Surg 2001;25:1296-1299.

9. Chang JH, Lee IS, Choi JY, et al. Biliary stricture after adult rightlobe living-donor liver transplantation with duct-to-duct anastomosis: long-term outcome and its related factors after endoscopic treatment. Gut Liver 2010;4:226-233.

10. Yazumi S, Yoshimoto T, Hisatsune H, et al. Endoscopic treatment of biliary complications after right-lobe living-donor liver transplantation with duct-to-duct biliary anastomosis. J Hepatobiliary Pancreat Surg 2006;13:502-510.

11. Tsujino T, Isayama $\mathrm{H}$, Sugawara $\mathrm{Y}$, et al. Endoscopic management of biliary complications after adult living donor liver transplantation. Am J Gastroenterol 2006;101:2230-2236.

12. Mahajani RV, Cotler SJ, Uzer MF. Efficacy of endoscopic management of anastomotic biliary strictures after hepatic transplanta- tion. Endoscopy 2000;32:943-949.

13. Morelli J, Mulcahy HE, Willner IR, Cunningham JT, Draganov P. Long-term outcomes for patients with post-liver transplant anastomotic biliary strictures treated by endoscopic stent placement. Gastrointest Endosc 2003;58:374-379.

14. Schwartz DA, Petersen BT, Poterucha JJ, Gostout CJ. Endoscopic therapy of anastomotic bile duct strictures occurring after liver transplantation. Gastrointest Endosc 2000;51:169-174.

15. Lee HW, Suh KS, Shin WY, et al. Classification and prognosis of intrahepatic biliary stricture after liver transplantation. Liver Transpl 2007;13:1736-1742.

16. Hwang S, Lee SG, Sung KB, et al. Long-term incidence, risk factors, and management of biliary complications after adult living donor liver transplantation. Liver Transpl 2006;12:831-838.

17. Seo JK, Ryu JK, Lee SH, et al. Endoscopic treatment for biliary stricture after adult living donor liver transplantation. Liver Transpl 2009;15:369-380.

18. Lee YY, Gwak GY, Lee KH, et al. Predictors of the feasibility of primary endoscopic management of biliary strictures after adult living donor liver transplantation. Liver Transpl 2011;17:1467-1473.

19. Koneru B, Sterling MJ, Bahramipour PF. Bile duct strictures after liver transplantation: a changing landscape of the Achilles' heel. Liver Transpl 2006;12:702-704.

20. Kim TH, Lee SK, Han JH, et al. The role of endoscopic retrograde cholangiography for biliary stricture after adult living donor liver transplantation: technical aspect and outcome. Scand J Gastroenterol 2011;46:188-196.

21. Thuluvath PJ, Pfau PR, Kimmey MB, Ginsberg GG. Biliary complications after liver transplantation: the role of endoscopy. Endoscopy 2005;37:857-863.

22. Zoepf T, Maldonado-Lopez EJ, Hilgard P, et al. Balloon dilatation vs. balloon dilatation plus bile duct endoprostheses for treatment of anastomotic biliary strictures after liver transplantation. Liver Transpl 2006;12:88-94.

23. Ben-Ari Z, Weiss-Schmilovitz H, Sulkes J, et al. Serum cholestasis markers as predictors of early outcome after liver transplantation. Clin Transplant 2004;18:130-136.

24. Hussaini SH, Sheridan MB, Davies M. The predictive value of transabdominal ultrasonography in the diagnosis of biliary tract complications after orthotopic liver transplantation. Gut 1999;45:900-903.

25. Tashiro H, Itamoto T, Sasaki T, et al. Biliary complications after duct-to-duct biliary reconstruction in living-donor liver transplantation: causes and treatment. World J Surg 2007;31:2222-2229.

26. Kao D, Zepeda-Gomez S, Tandon P, Bain VG. Managing the postliver transplantation anastomotic biliary stricture: multiple plastic versus metal stents: a systematic review. Gastrointest Endosc 2013;77:679-691

27. Park JS, Kim MH, Lee SK, et al. Efficacy of endoscopic and percutaneous treatments for biliary complications after cadaveric and living donor liver transplantation. Gastrointest Endosc 2003:57:78-85. 
134 Gut and Liver, Vol. 14, No. 1, January 2020

28. Verdonk RC, Buis CI, Porte RJ, et al. Anastomotic biliary strictures after liver transplantation: causes and consequences. Liver Transpl 2006;12:726-735.

29. Ryu CH, Lee SK. Biliary strictures after liver transplantation. Gut Liver 2011;5:133-142.

30. Kurita A, Kodama Y, Minami R, et al. Endoscopic stent placement above the intact sphincter of Oddi for biliary strictures after living donor liver transplantation. J Gastroenterol 2013;48:1097-1104.

31. Tarantino I, Mangiavillano B, Di Mitri R, et al. Fully covered selfexpandable metallic stents in benign biliary strictures: a multicenter study on efficacy and safety. Endoscopy 2012;44:923-927. 